\title{
Acute Renal Failure in the Elderly, over the Age of 75, in the Medical and Rehabilitation Hospital of Saint-Maurice (Paris - France)
}

Alpha Oumar $\mathrm{BAH}^{1^{*}}$, Mamadou Lamine Yaya BAH ${ }^{1}$, Renaud Pequignot ${ }^{2}$ and Oumou Kimso ${ }^{1}$

${ }^{1}$ Nephrology Department, Donka National Hospital, BP 234, Conakry, Guinea

${ }^{2}$ Medical and Rehabilitation Department of Saint Maurice Hospital of Paris - France

\begin{abstract}
Introduction: Acute renal failure (ARF) in the elderly is a common occurrence and will increase because of the aging population. Even though the elderly can develop any type of ARF, they are more exposed to iatrogenic ones due to polymedication.
\end{abstract}

Objective: To determine the frequency of the ARF in the elderly over 75 , and evaluate its impact on mortality.

Methods: This is a retrospective study conducted in 2011 at the medical and Rehabilitation Hospital of SaintMaurice. Were included, all patients aged 75 and over with an ARF, hospitalized during the study period.

Results: Fifty-six patients of which 23 men $(41 \%)$ and 33 women (59\%) were included from a total of 209 patients; a frequency of $26.8 \%$. The mean age was of $86.5 \pm 6$ years. The mean creatinine clearance level was of $17.2 \pm 40.8$ $\mathrm{ml} / \mathrm{min}$ (MDRD). Twenty-eight of our patients were on diuretics i.e. $50 \%$. The average hospital stay was of 78 days in patients with ARF against 33 days in those who did not have ARF. We recorded 8 deaths, including six in those with acute renal failure $(10.7 \%)$

Conclusion: Acute renal failure in the elderly is a common disease that is a common morbid event. Prevention relies on the preservation of the extracellular volume and should be a marker for quality health care.

Keywords: Acute renal failure; Elderly; Saint maurice hospitals

\section{Introduction}

The world's population is growing and aging. According to some projections, the proportion of people over 60 years will be multiplied by three and for those over 80 years by ten in the next century [1].

In France, the proportion of people 75 years of age and over is $8 \%$, it will be of $14 \%$ in 2030 and will approach $20 \%$ in 2050 . The physiological aging of kidneys is almost always asymptomatic [2]. The incidence of acute renal failure varies, from $0.17 \%$ in the general adult population, to $2 \%$ in a population of inpatients at a teaching hospital, and up to 16 $33 \%$ in patients in the ICU [3]. In the elderly, the incidence of ARF is estimated to be 950 cases per million populations [2].

For those over 65 years, it is about three to ten times that of the general population and then increases with age [4].

The aim of our study was to determine the frequency of acute renal failure in the elderly over 75 years of age and evaluate its impact on mortality.

\section{Materials and Methods}

This is a retrospective study done at the Medical and Rehabilitation department of Saint-Maurice Hospital in France. In this study, we included patients with acute renal failure whose age was greater than or equal to 75 years, hospitalized in the service from December 1st to December 31st, 2011. We're not included those with normal renal function. The creatinine clearance was calculated using the MDRD formula. Acute renal failure was defined as a rise in serum creatinine of at least $25 \%$ above the baseline value and above $100 \mu \mathrm{mol} / \mathrm{l}$ with the time of onset or disappearance is less than three months. Acute renal failure has been classified as recommended by KDIGO [5]. The disappearance of acute renal failure was defined as the return of serum creatinine to baseline level in the three months following the elevation of the base value of plasma creatinine. This was defined as the lowest value of creatinine found in the record plus a margin of $10 \%$.

\section{Results}

Out of the 209 patients, 56 were included into the study with a proportion of $26.8 \%$. They were 23 men (41\%) and 33 women (59\%). The mean age was $86.5 \pm 6$ years with extremes of 77 to 107 years. The mean creatinine clearance was $40.8 \pm 17.2 \mathrm{ml} / \mathrm{min}$ with extremes of 9-89 $\mathrm{ml} / \mathrm{min}$ (Table 1 ).

The mean duration of hospitalization of patients with ARF was of 78 days against 33 days for patients with normal renal function. ARF appeared within $24 \pm 18$ days of hospitalization with a range $1-73$ days in 31 patients. The usual metabolical complications of ARF were not found. Renal failures decreased during the hospitalization period in 36 patients within an average of $20.5 \pm 19$ days with a range of 2-84 days. We recorded 8 deaths out of 209 patients: 2 cases occurred in those who had no previous history of kidney disease (1.3\%) against 6 patients who had acute renal failure; representing a proportion of $10.7 \%$. Also 5 cases of death were recorded at 3 months in patients with an ARF (9\%).

\section{Discussion}

This retrospective study in this medical and rehabilitation hospital uses comments. Indeed, advanced age, comorbidities, iatrogenic causes increase the risk of onset and development of renal failure. This study was limited by the absence of several data from existing folders.

*Corresponding author: Alpha Oumar BAH, Nephrology, Donka National Hospital BP 234 Conakry, Guinea, Tel: +224 622218375; E-mail: bahalphaoumar1@gmail.com

Received: June 07, 2015; Accepted: October 06, 2015; Published: October 12, 2015

Citation: Alpha Oumar BAH, Mamadou LY BAH, Pequignot R, Kimso O (2015) Acute Renal Failure in the Elderly, over the Age of 75, in the Medical and Rehabilitation Hospital of Saint-Maurice (Paris - France). J Nephrol Ther 5: 217. doi:10.4172/2171 0959.1000217

Copyright: (C) 2015 Alpha Oumar BAH, et al. This is an open-access article distributed under the terms of the Creative Commons Attribution License, which permits unrestricted use, distribution, and reproduction in any medium, provided the original author and source are credited. 


\begin{tabular}{|c|l|c|c|}
\hline S. No & Causes & $\begin{array}{c}\text { Number } \\
\text { cases }\end{array}$ & $\%$ \\
\hline 1 & Medication & 28 & 50 \\
\hline & Diuretics & 11 & 19.6 \\
\hline & Angiotensin converting enzyme inhibitors & 1 & 1.9 \\
\hline 2 & Non steroid antiflammatory drugs & 5 & 9 \\
\hline 3 & Functional Hypovolemia & 4 & 7 \\
\hline 4 & Infectious: septic choc & 16 & 28.6 \\
\hline 5 & Heart failure & 11 & 19.6 \\
\hline
\end{tabular}

Table 1: Distribution of patients according to the causes of the ARF.

Fifty-six patients had ARF, $26.8 \%$ of a total of 209 elderly patients hospitalized in the ward during the study period. Akposso et al. retrospective study reported a significant increase in octogenarians being treated for acute renal failure: $10 \%$ in $1980 ; 40 \%$ in the 1990 s [6]. Mc Innes found that it was present in $7 \%$ of people hospitalized in geriatrics [7]. The high frequency of the ARF in the elderly could be explained both by the functional changes in the kidney and the renal impact of many chronic diseases such as diabetes, hypertension and obstructive diseases of the urinary tract, whose incidence increases with age. Note also the increasing share of iatrogenic causes as a risk factor for acute renal failure in the elderly frequently exposed to polymedication. We observed that patients with ARF had an average hospital stay of two and a half times longer than that of other patients, making ARF a major determinant of hospital stay. On the other hand, Viallon et al. had found in their study that acute renal failure did not affect the average length of hospital stays. They found it to be similar in patients with severe renal failure and others: $14 \pm 10$ versus $13.5 \pm 9$ days [8]. From an economic point of view, with an average cost of 464 Euros per day, hospitalization cost an average 36,200 Euros for patients with ARF against 15,300 Euros for other patients with normal renal function. In our series, we observed that $50 \%$ of patients were taking diuretics. Viallon Allain et al. meanwhile found in their study that diuretics were prescribed in $40 \%$ of patients with creatinine clearance less than $30 \mathrm{ml} / \mathrm{min}$ and in $41 \%$ of patients with a creatinine clearance greater than or equal to $30 \mathrm{ml} / \mathrm{min}$ [8]. This suggests that diuretics have a big responsibility in the occurrence of the ARF in the elderly. Other causes found, sixteen patients had heart failure (28.6\%). Akposso had found in his study that $40 \%$ of patients had cardiovascular disease and 11 patients had acute renal failure in the aftermath of surgery (19.6\%) [6]. Novis et al. estimate that the overall incidence of acute renal failure due to surgical origins is assessed to be 0.1 to $2 \%$ for any type of surgery [9]. In our series 5 patients (9\%) had hypovolemia with extracellular dehydration due to gastrointestinal loss (diarrhea, vomiting) and 4 patients had ARF after septic shock (7\%). Pascual et al. believe that septic shock provides a large contingent of ARF in the proportions of $15 \%$ [10]. The two most common mechanisms in the elderly are, firstly, relative or absolute hypovolemic causing "pre renal" or functional kidney failure and the other, obstacles on the urinary tract [11]. The death rate was multiplied by 8 in patients with acute renal failure in a population including all age groups; however, Gentric et al. observed a $90 \%$ survival at 39 months [12]. More than ARF itself, the pathology which it complicates is probably responsible for death; particularly acute dehydration and cardiac failure.

\section{Conclusion}

Acute renal failure in the elderly is a common condition whose presence is associated with a significant prolonging of hospitalization and additional cost of treatment on one hand, and secondly to severe excess mortality (multiplied by 8 ). Prevention of acute renal failure in the elderly which at the source is the preservation of extracellular volume could be a marker of quality of care.

\section{References}

1. Clèdes J, Hanrotel-Saliou C, Perrichot R, Strullu B, Tanquerel T (2002) Evolution kidney during aging. Néphrologie18: 13

2. Laurette A, Heng AE, Jaubert D, Ali A (2012) Acute renal failure in the elderly. Nephrology \& Therapeutics $8: 57-62$.

3. Payen D, Berton C (2005) Acute renal failure: epidemiology, incidence and prognostic criteria. French Annales anesthesia and resuscitation 24 :134-139.

4. Clèdes J, Saliou HC, Perrichot R, Strullu B, Tanquerel T (2002) Vascular and hereditary kidney disease, acute renal failure in the elderly. Néphrologie 18: 12.

5. Wanner C, Tonelli M (2014) KDIGO Clinical Practice Guideline for Lipid Management in CKD: summary of recommendation statements and clinical approach to the patient. Kidney International 85: 1303-1309.

6. Akposso K, Hertig A, Couprie R, Flahaut A, Alberti C, et al. (2000) Acute renal failure in patients overs 80 years old: 25 - year experience. Intensive care Med 26: 400-406.

7. Mc Innes EG, Levy DW, Chaudhuri MD, Bhan GL (1987) Renal failure in the elderly. QJ Med 64 :583-588.

8. Viallon A, Guyomarch P, Marjollet O, Belin M, Robert F, et al. (2006) Creatinine clearance and drug prescriptions for the elderly A study of 419 patients older than 70 years admitted through the emergency department. Medical Press 35: 413-417.

9. Novis BK, Roizen MF, Aronson S, Thisted RA (1994) Association of preoperative risk factors with postoperative acute renal failure. Anesth Analg 78: 143-149.

10. Pascual J, Liano F, Ortuno J (1995) The elderly patient with acute renal failure. J Am Soc Nephrol 6: 144-153.

11. Jerkic M, Vojvodic S, Lopez-Novoa JM (2001) The mechanism of increased renal susceptibility to toxic substances in the elderly Part I: The role of increased vasoconstriction. Int Urol Nephrol 32: 539-547.

12. Gentric A, Cledes J (1991) Immediate and long-term prognosis in acute renal failure in the elderly. Nephrol Dial Transplant 6: 86-90. 